\title{
Identification of the scatter in high cycle fatigue from temperature measurements
}

\author{
Cédric Doudard $^{\text {a }}$, Sylvain Calloch ${ }^{\text {a }}$, François Hild ${ }^{\text {a }}$, Philippe Cugy ${ }^{\text {b }}$, André Galtier ${ }^{\text {b }}$ \\ a LMT-Cachan, ENS de Cachan / CNRS UMR 8535 / Université Paris 6, 61 Avenue du Président Wilson, \\ F-94235 Cachan Cedex, E-mail: \{doudard,calloch,hild\}@Imt.ens-cachan.fr \\ b IRSID-Arcelor, voie romaine, BP 30320, F-57283 Maizières-lès-Metz Cedex
}

\begin{abstract}
It is proposed to determine the scatter in a Wöhler diagram by analyzing temperature changes induced by microplasticity. A unified framework is introduced to study both phenomena. The identification procedure is applied to a dual-phase steel. (C) 2001 Académie des sciences/Éditions scientifiques et médicales Elsevier SAS

Fatigue/ Microplasticity/ Poisson point process/ Weibull model

Identification de la dispersion des limites d'endurance à l'aide d'un essai d'échauffement

Résumé. Une détermination de la dispersion dans un diagramme de Wöhler est proposée à partir de l'évolution de la température induite par de la microplasticité. Un cadre unifié est introduit pour décrire ces deux phénomènes. La procédure d'identification est appliquée à un acier biphasé. (C) 2001 Académie des sciences/Éditions scientifiques et médicales Elsevier SAS

Fatigue/Microplasticité/ Processus ponctuel de Poisson / Modèle de Weibull
\end{abstract}

\section{Version française abrégée}

Les essais d'échauffement peuvent être utilisés pour déterminer les limites d'endurance de métaux et alliages [1, 2, 3]. Lors de cycles de chargement, la température stationnaire est évaluée, et il est observé qu'après une certaine limite, cette température croît de manière significative. Ceci correspond à un dépassement de la limite d'endurance, au-dessus de laquelle se produit une activité microplastique qui engendre une dissipation intrinsèque. Il est proposé de décrire ce phénomène en utilisant une approche probabiliste qui soit également pertinente en fatigue à grand nombre de cycles (i.e., capable de décrire la dispersion des limites d'endurance).

L'évolution de la température est écrite en considérant un ensemble de grains élasto-plastiques (appelés inclusions) entourés d'une matrice élastique. Le volume de chaque inclusion est noté $V_{0}$ et devient actif (i.e., la microplasticité décrite par une contrainte d'écoulement $\sigma_{y}$ se produit) pour une contrainte équivalente (e.g., de von Mises) $\sigma_{e} \geqslant \sigma_{y}$. Les centres des inclusions actives sont distribués aléatoirement et obéissent à

\section{Note présentée par First name NAME}

S1620-7742(01)0xxxxx-x/FLA

(C) 2001 Académie des sciences/Éditions scientifiques et médicales Elsevier SAS. Tous droits réservés. 


\section{Doudard, S. Calloch, F. Hild, P. Cugy, A. Galtier}

un processus ponctuel de Poisson d'intensité $\lambda$ qui dépend du niveau de chargement $[4,5]$. La probabilité $P_{k}(\Omega)$ de trouver $k$ sites actifs dans un domaine $\Omega$ de volume $V$ suit une loi de Poisson (1) où $N(\Omega)$ est le nombre moyen de défauts qui est relié à l'intensité $\lambda$ par (2) où $S_{0}$ et $m$ sont des paramètres matériels. Le tenseur des contraintes dans l'inclusions $\sigma$ est relié au tenseur des contraintes macroscopiques $\boldsymbol{\Sigma}$ par (4), où $\epsilon^{p}$ est le tenseur de déformation plastique, $\mu$ le module de cisaillement et $\beta$ une constante dépendant du coefficient de Poisson du matériau [6]. L'énergie libre $\rho \psi$ associée à une inclusion élasto-plastique à écrouissage cinématique est écrite en (5) [7], où $\epsilon^{e}$ est le tenseur des déformations élastiques (une décomposition additive des déformations est utilisée), $\boldsymbol{\epsilon}^{\text {th }}$ le tenseur des déformations de dilatation thermique, $\mathcal{K}$ le tenseur d'élasticité, $C$ une constante de proportionnalité de la loi d'écrouissage, ' :' le produit contracté sur deux indices, $T_{0}$ une température de référence, $\theta$ un incrément de température relatif à $T_{0}$ supposé rester faible de telle manière que le dernier terme de (5) est simplifié et la capacité calorifique $c$ est une constante. Pour une loi d'écrouissage cinématique linéaire, la dissipation intrinsèque $\delta$ dans une inclusion ayant une limite d'écoulement $\sigma_{y}$ au cours d'un cycle de chargement d'amplitude $\Sigma_{0}$ est donnée en (6) où $h$ est le module d'écrouissage et $\langle$.$\rangle la partie positive de '$. . Pour un processus ponctuel de Poisson, $V \frac{\mathrm{d} \lambda}{\mathrm{d} \Sigma} \mathrm{d} \Sigma$ est le nombre d'inclusions activées pour une contrainte équivalente variant de $\Sigma$ à $\Sigma+\mathrm{d} \Sigma$ dans un domaine $\Omega$ de volume $V$; l'énergie dissipée sur un cycle étant égale à $\delta\left(\Sigma, \Sigma_{0}\right)$. La densité globale d'énergie dissipée sur un cycle $\Delta$ est obtenue en considérant l'ensemble de tous les sites actifs pour une amplitude $\Sigma_{0}(7)$; elle induit une variation de température qui est calculée en résolvant l'équation de la chaleur (8), où $f_{r}$ est la fréquence de chargement, $\tau$ un temps caractéristique dépendant des conditions aux limites thermiques [8, 9] et $\Theta$ la température macroscopique . La température stationnaire $\bar{\Theta}$ est donnée en (9). L'analyse de l'évolution de cette dernière en fonction de $\Sigma_{0}$ permet d'identifier la puissance $m$ du processus ponctuel de Poisson, caractéristique de la microstructure.

L'amorçage de fissures est décrit par une énergie critique $E_{c}[10]$ associée à la dissipation $\delta$ cumulée (10) sur un nombre de cycles $N_{F}$. Pour chaque limite d'écoulement $\sigma_{y}$, le nombre de cycles à rupture (assimilé à celui d'amorçage) est relié à l'amplitude $\Sigma_{0}$ par (11) où $\Sigma_{s}$ est une constante dépendant de $E_{c}, h$ and $V_{0}$. L'équation (11) correspond à une loi de Stromeyer [11,12] lorsque la limite d'écoulement $\sigma_{y}$ est prise égale à la limite d'endurance $\Sigma_{D}$. Les inclusions considérées précédemment sont supposées être la cause de la rupture en fatigue à grand nombre de cycles (FGNC). En FGNC, une hypothèse du maillon le plus faible [13] s'applique souvent : la première inclusion critique (i.e., le critère (11) est satisfait) conduit à la rupture de la structure [12]. La probabilité de rupture $P_{F}$ d'un échantillon chargé uniformément est donnée en (12). En notant que l'intensité $\lambda$ est décrite par une fonction puissance de l'amplitude de contrainte (3), un modèle de Weibull [14] décrit la dispersion des limites d'endurance. Les paramètres $m$ et $V_{0} S_{0}^{m}$ correspondent à ceux d'un modèle de Weibull à deux paramètres (le module de Weibull $m$ peut ainsi être identifié à partir d'essais d'échauffement). Lorsque le champ de contrainte est hétérogène, les résultats précédents peuvent être généralisés en considérant le volume effectif [15] $V_{\text {eff }}$ à la place de $V$ dans (12). On peut ainsi tracer un diagramme de Wöhler en notant qu'une iso-probabilité de rupture est décrite par (13).

L'analyse précédente est appliquée à un acier biphasé (désignation Arcelor : DP60) pour lequel l'amorçage se produit au voisinage d'inclusions de martensite [16]. La figure 1-a montre l'évolution de la température stationnaire $\bar{\Theta}$ en fonction de l'amplitude $\Sigma_{0}$ lors d'un essai de traction/compression (rapport de charge $R=-1$ ) pour une fréquence $f_{r}=10 \mathrm{~Hz}$ avec une seule éprouvette. Une valeur $m=12.4$ est obtenue. Les deux coefficients de la loi de Stromeyer sont obtenus à partir de la courbe de Wöhler (figure 1-b) qui décrit la dépendance moyenne du nombre de cycles à rupture avec l'amplitude de contrainte $\Sigma_{0}$. Une limite d'endurance moyenne $\bar{\Sigma}_{D}=250 \mathrm{MPa}$ et $\Sigma_{s}=40 \mathrm{GPa}$ sont identifiées. À partir de ces deux données, les paramètres de Weibull peuvent être identifiés (14) où $\Gamma$ est la fonction d'Euler de seconde espèce. La figure 2 montre une reconstruction satisfaisante du diagramme de Wöhler avec les dispersions pour l'acier étudié.

L'approche proposée permet de relier les résultats d'essais d'échauffement à la dispersion en fatigue à grand nombre de cycles. Ceci permet une estimation rapide de la dispersion en utilisant une éprouvette pour l'essai d'échauffement et environ une dizaine d'éprouvettes pour obtenir une courbe de Wöhler. Une 
analyse directe de la dispersion nécessiterait au moins 30 à 50 essais.

Temperature measurements are used to evaluate the fatigue limit of metals and alloys [1, 2, 3]. By cycling a sample and determining the steady-state temperature for different stress levels, it is observed that beyond a given limit, the steady-state temperature starts to increase significantly. This regime change corresponds to a situation where the fatigue limit is exceeded. Above the latter, crack initiation induced by microplasticity occurs and the associated intrinsic dissipation can explain the temperature change. It is proposed to describe this phenomenon by using a probabilistic approach that is also relevant in high cycle fatigue (i.e., able to describe the scatter of fatigue limits).

\section{Temperature change}

The aim of this first section is to evaluate the temperature change in a cyclic test for different stress levels in the presence of microplastic activity. The latter is accounted for by considering a set of elastoplastic grains, referred to as inclusions, randomly distributed within an elastic matrix. The volume of each inclusion is denoted by $V_{0}$ and it becomes active (i.e., microplasticity described by a yield stress $\sigma_{y}$ occurs) for an equivalent (e.g., von Mises) stress level $\sigma_{e} \geqslant \sigma_{y}$ that is random. The centers of the inclusions are assumed to follow a Poisson point process of intensity $\lambda[4,5]$. The probability $P_{k}(\Omega)$ of finding $k$ active sites in a domain $\Omega$ of volume $V$ follows a Poisson distribution

$$
P_{k}(\Omega)=\frac{[N(\Omega)]^{k}}{k !} \exp [-N(\Omega)]
$$

where $N(\Omega)$ is average number of active sites, so that the intensity of the Poisson point process $\lambda$ is the average density of active sites in a domain $\Omega$

$$
N(\Omega)=\lambda V
$$

The intensity of the Poisson point process depends on an overall equivalent stress amplitude $\Sigma_{e}$

$$
\lambda\left(\Sigma_{e}\right)=\frac{1}{V_{0}}\left(\frac{\Sigma_{e}}{S_{0}}\right)^{m},
$$

where $S_{0}$ and $m$ are material-dependent parameters. Equation (3) shows that the higher $\Sigma$, the more sites are active (i.e., inclusions for which the yield stress $\sigma_{y}$ is exceeded). In the present case, it is assumed that the active sites are distributed within a considered volume. A similar analysis can be performed when the initiation sites are located on the surface of a sample. The plastic inclusion is assumed to be surrounded by an elastic matrix. The stress tensor in the plastic inclusion $\boldsymbol{\sigma}$ is related to the macroscopic stress tensor $\boldsymbol{\Sigma}$ by

$$
\boldsymbol{\sigma}=\boldsymbol{\Sigma}-2 \mu(1-\beta) \boldsymbol{\epsilon}^{p},
$$

where $\epsilon^{p}$ is plastic strain tensor, $\mu$ the shear modulus and $\beta$ is a constant related to the Poisson's ratio of the material [6].

The free energy $\rho \psi$ associated to an elasto-plastic inclusion with kinematic hardening is written as [7]

$$
\rho \psi=\frac{V_{0}}{2} \boldsymbol{\epsilon}^{e}: \mathcal{K}: \boldsymbol{\epsilon}^{e}-V_{0} \boldsymbol{\epsilon}^{e}: \mathcal{K}: \boldsymbol{\epsilon}^{t h}(\theta)+\frac{C V_{0}}{3} \boldsymbol{\epsilon}^{p}: \boldsymbol{\epsilon}^{p}-\frac{V_{0} c \theta^{2}}{2 T_{0}},
$$

where $\boldsymbol{\epsilon}^{e}$ denotes the elastic strain tensor (an additive strain decomposition is used herein), $\boldsymbol{\epsilon}^{\text {th }}(\theta)$ the thermal strain tensor, $\mathcal{K}$ the fourth order elasticity tensor, $C$ the proportionality parameter of a linear kinematic 


\section{Doudard, S. Calloch, F. Hild, P. Cugy, A. Galtier}

hardening law, ' $'$ ' the tensorial product contracted with respect to two indices, $T_{0}$ a reference temperature, $\theta$ a temperature change with respect to $T_{0}$ assumed to remain small so that the last term in Eqn. (5) is simplified and the heat capacity $c$ is temperature-independent. For a linear kinematic hardening law, the corresponding intrinsic dissipated energy $\delta$ in one inclusion over a loading cycle for a given value of the yield stress $\sigma_{y}$ and stress amplitude $\Sigma_{0}$ (in the case of proportional load history, $\Sigma_{e} \equiv \Sigma_{0}$ ) can be expressed as

$$
\delta\left(\sigma_{y}, \Sigma_{0}\right)=\frac{4 V_{0} \sigma_{y}}{h}\left\langle\Sigma_{0}-\sigma_{y}\right\rangle,
$$

where $h$ is the hardening modulus [i.e., $h=C+3 \mu(1-\beta)$ ] and $\langle$.$\rangle the Macauley brackets (i.e., positive$ part of '.'). With a Poisson point process, $V \frac{\mathrm{d} \lambda}{\mathrm{d} \Sigma} \mathrm{d} \Sigma$ is the number of inclusions activated for an equivalent stress ranging from $\Sigma$ to $\Sigma+\mathrm{d} \Sigma$ in a domain $\Omega$ of volume $V$, i.e., the number of sites whose mean fatigue limit lies between $\Sigma$ and $\Sigma+\mathrm{d} \Sigma$, and whose dissipated energy during a load cycle is $\delta\left(\Sigma, \Sigma_{0}\right)$. The global dissipated energy density per cycle $\Delta$ becomes

$$
\Delta\left(\Sigma_{0}\right)=\int_{0}^{\Sigma_{0}} \delta\left(\Sigma, \Sigma_{0}\right) \frac{\mathrm{d} \lambda}{\mathrm{d} \Sigma}(\Sigma) \mathrm{d} \Sigma=\frac{4 m}{h(m+1)(m+2)} \frac{\Sigma_{0}^{m+2}}{S_{0}^{m}} .
$$

The dissipated energy per cycle $\Delta$ induces a temperature variation that can be evaluated by solving the heat conduction equation. In the latter, the only relevant source term is $\Delta$, which is scaled by the load frequency $f_{r}$

$$
\dot{\Theta}+\frac{\Theta}{\tau}=\frac{\Delta\left(\Sigma_{0}\right) f_{r}}{\rho c},
$$

where $\tau$ is a characteristic time that depends on the heat transfer boundary conditions $[8,9]$ and $\Theta$ the overall temperature. The corresponding steady-state temperature $\bar{\Theta}$ reads

$$
\bar{\Theta}=\frac{4 f_{r} \tau m}{h \rho c(m+1)(m+2)} \frac{\Sigma_{0}^{m+2}}{S_{0}^{m}} .
$$

Equation (9) shows that, because of the assumption of a gradual activation of microplasticity, there is a gradual change of the steady-state temperature $\bar{\Theta}$ with the applied stress amplitude $\Sigma_{0}$. The analysis of temperature measurements allows one to determine the power $m$ describing the temperature variation and characterizing the underlying random microstructure (i.e., the higher $m$, the smaller the scatter of the yield stress $\sigma_{y}$ ).

\section{Scatter of the fatigue limits}

By using the same hypotheses on the material microstructure, the present section aims at analyzing the scatter in high cycle fatigue. It is assumed that microcrack initiation is described by a critical value $E_{c}$ of the cumulative dissipated energy for each inclusion [10]

$$
N_{F} \delta\left(\sigma_{y}, \Sigma_{0}\right)=E_{c}
$$

where $N_{F}$ is the number of cycles to failure (i.e., the propagation stage is neglected with respect to the initiation stage). For each yield stress $\sigma_{y}$, the number of cycles to failure $N_{F}$ is related to the stress amplitude $\Sigma_{0}$ by

$$
N_{F}\left(\sigma_{y}, \Sigma_{0}\right)=\frac{\Sigma_{s}^{2}}{\sigma_{y}\left\langle\Sigma_{0}-\sigma_{y}\right\rangle},
$$

where $\Sigma_{s}$ is a constant depending on $E_{c}, h$ and $V_{0}$. Equation (11) corresponds to Stromeyer's law [11, 12] when the microscopic yield stress is related to a given fatigue limit $\Sigma_{D}$. Consequently, by using the previous thermodynamic approach, the coefficients of Stromeyer's law can be related to microplasticity 
within the material. In HCF, a weakest link assumption [13] usually applies. The first critical inclusion (i.e., criterion (11) is satisfied) causes the failure of a sample or structure [12]. Consequently, the failure probability $P_{F}$ of a uniformly loaded sample reads

$$
P_{F}=P_{k \geqslant 1}(\Omega)=1-\exp [-\lambda V]
$$

By using the intensity $\lambda$ expressed as a power law of the stress amplitude [see Eqn. (3)], a Weibull model [14] is retrieved for the fatigue limits. The parameters $m$ and $V_{0} S_{0}^{m}$ then correspond to those of the so-called two-parameter Weibull model. If the latter can be identified from temperature measurements, it is possible to relate the gradual temperature change (characterized by the power $m$ ) to the scatter in fatigue limits (described by the Weibull modulus $m$ ) since both are related to the intensity $\lambda$ of the Poisson point process. It can be noted that the results derived so far assume a uniform macroscopic state of stress. They can be generalized to heterogeneous situations in which an effective volume [15] $V_{\text {eff }}$ is used instead of the total volume $V$ in Eqn. (12). Equation (12) describes the scatter of the fatigue limits. A constant failure probability is then obtained by combining Eqns. (12) and (11) in which the yield stress $\sigma_{y}$ corresponds to the fatigue limit $\Sigma_{D}$ for a given failure probability $P_{F}$

$$
N_{F}\left[\Sigma_{D}\left(P_{F}\right), \Sigma_{0}\right]=\frac{\Sigma_{s}^{2}}{\Sigma_{D}\left(P_{F}\right)\left\langle\Sigma_{0}-\Sigma_{D}\left(P_{F}\right)\right\rangle} .
$$

By using Eqns. (3), (12) and (13), it is possible to draw a Wöhler plot of a given material from data obtained from temperature measurements when one fatigue limit and $\Sigma_{s}$ are known.

\section{Identification strategy}

The previous analysis is now applied to a hot-rolled dual-phase steel (about 15 vol\% martensite and 85 vol\% ferrite, Arcelor designation: DP60). For this class of materials, initiation occurs around martensitic
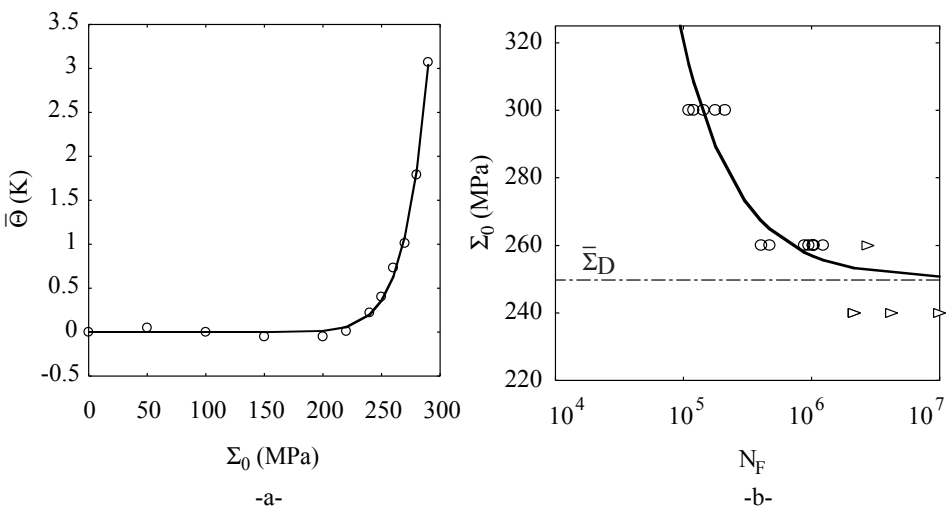

Figure 1: -a-Steady-state temperature $\bar{\Theta}$ vs. stress amplitude $\Sigma_{0}$ for a DP60 steel. -b-Wöhler Diagram of the same steel for tension/compression tests (load ratio $R=-1$ ). The open symbols are experimental data (triangle: no failure) and the solid line is the identification.

-a-Température stationnaire $\bar{\Theta}$ en fonction de l'amplitude de contrainte $\Sigma_{0}$ pour un acier DP60. b-Diagramme de Wöhler du même acier pour des essais de traction/compression (rapport de charge $R=-1$ ). Les symboles correspondent aux données expérimentales (triangle: essai interrompu) et le trait continu à l'identification.

sites within the volume of the material [16]. The temperature measurements are carried out on a single sample by recording the steady-state temperature after 3000 cycles before the stress level is increased and 


\section{Doudard, S. Calloch, F. Hild, P. Cugy, A. Galtier}

the procedure repeated. In Fig. 1-a, the steady-state temperature $\bar{\Theta}$ (here measured by a thermocouple) is plotted as a function of the stress amplitude $\Sigma_{0}$ in a tension/compression test (load ratio $R=-1$ ) for a frequency $f_{r}=10 \mathrm{~Hz}$. From these data, the value $m=12.4$ is obtained. The two coefficients of Stromeyer's law are determined from the analysis of the Wöhler curve (Fig. 1-b) where the average dependence of the number of cycles to failure with respect to the stress amplitude $\Sigma_{0}$. A (mean) fatigue limit $\bar{\Sigma}_{D}=250 \mathrm{MPa}$ and a stress $\Sigma_{s}=40 \mathrm{GPa}$ are obtained. From the knowledge of the mean fatigue limit, the last Weibull parameter $V_{0} S_{0}^{m}$ can be evaluated (since $m$ is known, so that the effective volume $V_{\text {eff }}$ can be calculated)

$$
\bar{\Sigma}_{D}=S_{0}\left(\frac{V_{0}}{V_{\mathrm{eff}}}\right)^{1 / m} \Gamma\left(1+\frac{1}{m}\right),
$$

where $\Gamma$ is the Euler function of the second kind. From these parameters, the scatter in fatigue limits as well as the overall scatter can be predicted. Figure 2 shows the results for the studied dual-phase steel. A good agreement is obtained.

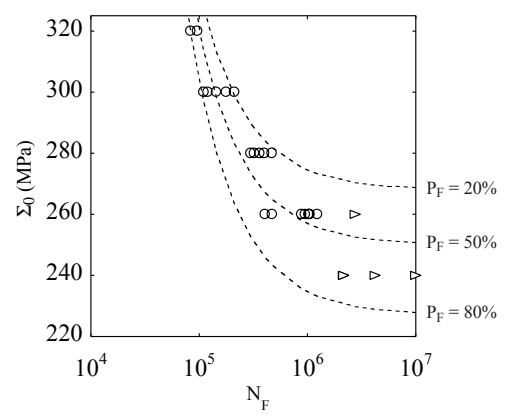

Figure 2: Prediction of three different failure probabilities $P_{F}$ in a Wöhler diagram for a DP60 steel. The open symbols are experimental data (triangle: no failure).

Prévision de trois courbes de probabilité de rupture $P_{F}$ dans un diagramme de Wöhler pour un acier DP60. Les symboles correspondent aux données expérimentales (triangle: essai interrompu).

\section{Summary}

The present approach relates temperature measurements to the scatter HCF. It allows for a fast estimate of the latter by using one sample for the temperature measurements and about 10 samples to obtain the classical Wöhler curve. A direct analysis of the scatter in HCF would require at least 30 to 50 samples.

\section{References}

[1] M.P. Luong, Fatigue limit evaluation of metals using an infrared thermographic technique, Mech. Mat. 28 (1998) 155-163.

[2] G. La Rosa, A. Risitano, Thermographic methodology for rapid determination of the fatigue limit of materials and mechanical components, Int. J. Fat. 22 (2000) 65-73.

[3] A. Galtier, O. Bouaziz, A. Lambert, Influence de la microstructure des aciers sur leurs propriétés mécaniques, Méc. Ind. 3 (2002) 457-462.

[4] R. Gulino, S.L. Phoenix, Weibull strength statistics for graphite fibres measured from the break progression in a model graphite/glass/epoxy microcomposite, J. Mater. Sci. 26 (1991) 3107-3118.

[5] D. Jeulin, Modèles morphologiques de structures aléatoires et changement d'échelle, thèse d'État, Université de Caen, 1991.

[6] M. Berveiller, A. Zaoui, An extension of the self-consistent scheme to plastically flowing polycrystals, J. Mech. Phys. Solids 26 (1979) 325-344. 


\section{Identification of the scatter in HCF}

[7] J. Lemaitre, J.-L. Chaboche, Mécanique des matériaux solides, Dunod, Paris (France), 1985.

[8] A.B. De Vriendt, La transmission de la chaleur, Morin, Québec (Canada) 1 (1987).

[9] A. Chrysochoos, H. Louche, An infrared image processing to analyse the calorific effects accompanying strain localisation, Int. J. Eng. Sci. 38 (2000) 1759-1788.

[10] F. Ellyin, K. Golos, Multiaxial Fatigue Damage Criterion, J. Eng. Mat. Tech. 110 (1988) 63-68.

[11] C.E. Stromeyer, The determination of fatigue limits under alternating stress conditions, Proc. Roy. Soc. A90 (1914) 411-425.

[12] W. Weibull, A statistical representation of fatigue failures in solids, Trans. Roy. Swed. Inst. Tech. 27 (1949).

[13] A.M. Freudenthal, Statistical approach to brittle fracture, in: Fracture, H. Liebowitz, Edt., Academic Press, New York (USA), 2 (1968) 591-619.

[14] W. Weibull, A statistical theory of the strength of materials, Roy. Swed. Inst. Eng. Res. 151 (1939).

[15] D.G.S. Davies, The statistical approach to engineering design in ceramics, Proc. Brit. Ceram. Soc. 22 (1973) 429-452.

[16] K. Nakajima, S. Kamiishi, M. Yokoe, T. Miyata, The influence of microstructural morphology and prestrain on fatigue crack propagation of dual-phase steels in the near-threshold region, ISIJ International 39 (1999) 486-492. 


\section{Doudard, S. Calloch, F. Hild, P. Cugy, A. Galtier}

Auteur correspondant :

\section{Cédric DOUDARD}

LMT-Cachan

61, avenue du Président Wilson

94235 Cachan Cedex

Tél : + 33147402242

Fax : + 33147402240 